\title{
Variation in Radiative Contribution by Clouds to Downward Longwave Flux
}

\author{
Kyohei YAMADA, Tadahiro HAYASAKA, and Hironobu IWABUCHI \\ Center for Atmospheric and Oceanic Studies, Graduate School of Science, Tohoku University, Sendai, Japan
}

(Manuscript received 31 October 2013, in final form 30 May 2014)

\begin{abstract}
Clouds strongly influence downward longwave radiative flux and affect the radiation budget at the surface. We evaluated the cloud radiative effect in both absolute and relative terms on downward longwave radiation at the surface; we considered variations in the cloud radiative effect with changes in cloud amount, precipitable water, and cloud base height, as measured by eight stations of the Baseline Surface Radiation Network. The downward longwave radiation predicted by a radiative transfer model agreed well with observations. The cloud radiative forcing and contribution ranged from -21 to $92 \mathrm{~W} \mathrm{~m}^{-2}$ and from $-6 \%$ to $38 \%$, respectively. The cloud effect shows a positive correlation to the shortwave diffusivity index (an index of cloud amount) and a negative correlation to precipitable water amount. The absolute effect values are small, depending on site conditions, but the relative effect values are larger under dry conditions than under humid conditions. Under humid conditions, the effect of the shortwave diffusivity index is very small. Under dry and cold conditions, such as those found in polar regions, negative values of cloud radiative contribution appear frequently because clouds absorb the emissions from temperature inversion layers. In comparison with prior research that used the A-Train satellite product, the present study shows a wider distribution and a larger maximum value for cloud forcing from amount of water vapor. Cloud effect has a roughly negative relationship with cloud base height, but a positive correlation with cloud base height occurs under low clouds at Tateno, which is located on the Pacific Ocean side of Japan. This correlation is because of the unusual relationship between cloud base height and cloud effect at Tateno during the summer and winter seasons. These results describe small-scale and near-surface variations in cloud effect, which are difficult to detect by satellite measurements.
\end{abstract}

Keywords longwave radiation; cloud effect; in situ observation

\section{Introduction}

Downward longwave radiation (DLR) influences climate change, the water cycle, and the radiation budget at the surface. Clouds are an important factor in DLR because they absorb and emit both downward and upward fluxes. Stephens (2005) reviewed the effect of clouds on radiative transfer and the climate system. Cloud cover, on average across

Corresponding author: Kyohei Yamada, Center for Atmospheric and Oceanic Studies, Graduate School of Science, Tohoku University, 6-3 Aoba Aramaki-aza Aoba-ku, Sendai 980-8578, Japan

E-mail: yamada@caos-a.geophys.tohoku.ac.jp

(C)2014, Meteorological Society of Japan
Earth, produces a radiative net cooling effect at the surface. The vertical location of clouds is important for the cloud effect. High clouds tend to warm the atmosphere, especially at low latitudes, whereas low clouds enhance cooling of the atmosphere, especially at high latitudes.

For longwave radiation, clouds warm the surface and the surface air. Sohn and Bennarts (2008) estimated the influence of cloud water path on upward longwave radiation at the top of the atmosphere (TOA) by using the Advanced Microwave Scanning Radiometer for the Earth Observing System. Their research indicated that the spatial variation in cloud upward longwave forcing was less than $5 \mathrm{~W} \mathrm{~m}^{-2}$ even in tropical regions, where convecting thick clouds 
are often present. Schmidt et al. (2010) estimated the global average contributions of water vapor, carbon dioxide, and clouds to upward longwave flux at the TOA to be $50 \%, 19 \%$, and $25 \%$, respectively. Stephens et al. (2012) calculated the global average downward longwave flux at the surface by four different methods and estimated the cloud radiative effect with data from A-Train satellites. The global average contribution of cloud for DLR was about 24-34 $\mathrm{W} \mathrm{m}^{-2}$. Arnfield (1979) compared some empirical methods for calculating DLR under clear-sky (Brunt 1932; Swinbank 1963; Idso and Jackson 1969) and all-sky conditions (Sellers 1965) at Simcoe, southern Ontario, during the period from July to September in 1969. Under clear-sky conditions, the primitive methods given in Swinbank (1963) and Idos and Jackson (1969), which use screened air temperature, were preferable over other parameterizations for calculating DLR. Under all-sky conditions, it was important to consider both cloud amount and cloud type.

Satellite observations aid in research on global and continuously changing phenomena. Wild et al. (1998) estimated the cloud effect at $24 \mathrm{~W} \mathrm{~m}^{-2}$ as a global average by ECHAM4 from the 10-year data from 1979 to 1988 . Zhang et al. (2004) showed that the global average for cloud effect is $31 \mathrm{~W} \mathrm{~m}^{-2}$ by analyzing the International Satellite Cloud Climatology Project satellite data for 1983 to 2001. Stephens et al. (2012) estimated the cloud effect as 24-34 $\mathrm{W} \mathrm{m}^{-2}$ from A-Train product for 2006 to 2009. However, estimation of DLR from satellite data is not sufficiently accurate. Henderson et al. (2013) used data from CloudSat and Cloud-Aerosol Lidar and Infrared Pathfinder Satellite Observations (CALIPSO) with Moderate-Resolution Imaging Spectroradiometer (MODIS) data for the 2006 to 2011 and estimated cloud radiative forcing by the BugsRad program (Ritter and Gleyn 1992). Longwave radiation exhibits large uncertainty because of insufficient precipitation at surface temperatures and lower tropospheric humidity (below $500 \mathrm{hPa}$ level). The error in cloud height is $\pm 240 \mathrm{~m}$ for CloudSat, and this error may affect surface radiation calculations by $1.5 \mathrm{~W} \mathrm{~m}^{-2}$ for surface DLR.

Clouds are complex and variable, and thus knowledge of the effects of clouds on DLR is limited. Although Yamada et al. (2012) estimated the contributions of water vapor, carbon dioxide, and clouds to DLR, the targeted clouds were limited to those thick enough to constitute an overcast condition. Most studies of the effect of clouds on DLR have used satellite data, dealt solely with the global average, or used in situ measurements in limited areas. Cloud effect on downward longwave flux varies with local conditions such as atmospheric temperature, humidity, and cloud characteristics. Because cloud and water vapor are dominant factors for longwave radiation, it is necessary to investigate the sensitivity of cloud effect to the condition of the atmosphere and cloud state. The purpose of this paper is to quantify the cloud effect on DLR in various cloud conditions from the subtropical zone to the Antarctic on the basis of in situ observations. We also examine the influences of cloud amount and precipitable water at eight observation stations and estimate the effect of cloud base height at four observation stations.

\section{Data and analysis}

\subsection{Estimation of cloud effect}

The absolute and relative effects of cloud on DLR are defined as cloud radiative forcing (CRF) and cloud radiative contribution (CRC) by formulas (1) and (2), respectively:

$$
\begin{aligned}
& C R F=D L R_{\text {Obs }}^{A l l}-D L R_{\text {Cal }}^{\text {Clear }}\left[\mathrm{W} \mathrm{m}^{-2}\right], \\
& C R C=\frac{C R F}{D L R_{O b s}^{A l l}}[\%],
\end{aligned}
$$

where $D L R_{O b s}^{A l l}$ is the observed downward longwave flux at the surface under the all-sky condition and $D L R_{\text {Cal }}^{\text {Clear }}$ is the calculated downward longwave flux at the surface under the clear-sky condition.

\subsection{Observation data}

The following data were collected at eight stations of the Baseline Surface Radiation Network (BSRN; http://www.bsrn.awi.de/; Ohmura et al. 1998): the surface downward radiation, vertical profiles of temperature and relative humidity by radiosonde observations, and corresponding meteorological observation data. For flux observations, BSRN aims to achieve errors of less than $5 \%$ in relative measurements or less than $10 \mathrm{~W} \mathrm{~m}^{-2}$ in absolute measurements. Table 1 provides descriptions of the observation stations. Figure 1 gives the locations of the stations. All stations have altitudes below $200 \mathrm{~m}$. ISH (Ishigaki island, Japan), which is the hottest and wettest of the stations, has an annual average surface air temperature $\left(\mathrm{T}_{\mathrm{S}}\right)$ of about $298 \mathrm{~K}$ and an average precipitable water (PW) of about $46 \mathrm{~mm}$. The annual average $D L R_{O b s}^{A l l}$ is $407 \mathrm{~W} \mathrm{~m}^{-2}$. In contrast, the annual averages of $\mathrm{T}_{\mathrm{S}}, \mathrm{PW}$, and $D L R_{O b s}^{A l l}$ at SYO (Showa 
Table 1. Description of site conditions. $D L R_{O b s}^{A l l}$ : Observed DLR at the surface under all-sky conditions [W m $\left.{ }^{-2}\right], \mathrm{T}_{\mathrm{S}}: \mathrm{Surface}$ air temperature $[\mathrm{K}], \mathrm{RH}_{\mathrm{S}}$ : Surface air relative humidity [\%], PW: Precipitable water [mm], SDI: Shortwave diffusivity index $[0-1]$.

\begin{tabular}{|c|c|c|c|c|c|c|c|}
\hline \multirow[b]{2}{*}{ Station } & \multirow[b]{2}{*}{ Abbr. } & \multicolumn{6}{|c|}{ Station description } \\
\hline & & Country & Lat. & Long. & Alt. & Time Period & Time \\
\hline Bermuda & BER & Bermuda, UK & 32.2670 & -64.6670 & 8 & 2004-2005 & 12 \\
\hline Fukuoka & FUA & Japan & 33.5817 & 130.3750 & 3 & 2010-2012 & 00 \\
\hline Ishigakijima & ISH & Japan & 24.3367 & 124.1633 & 6 & 2010-2012 & 00 \\
\hline Lindenberg & LIN & Germany & 52.2100 & 14.12220 & 125 & $2001-2006$ & $06,12,18$ \\
\hline Ny-Ålesund & NYA & Ny-Ållesund, Spitsbergen & 78.9250 & 11.9300 & 11 & 2001-2011 & 12,18 \\
\hline Sapporo & SAP & Japan & 43.0600 & 141.3283 & 17 & 2010-2012 & 00 \\
\hline Syowa & SYO & Cosmonaut Sea, Antarcatica & -69.0050 & 39.5890 & 18 & 2001-2011 & 00,12 \\
\hline \multirow[t]{3}{*}{ Tateno } & TAT & Japan & 36.0500 & 140.1333 & 25 & 1996-2012 & 00 \\
\hline & & & {$\left[{ }^{\circ} \mathrm{N}\right]$} & {$\left[{ }^{\circ} \mathrm{E}\right]$} & {$[\mathrm{m}]$} & & [UTC] \\
\hline & & \multicolumn{6}{|c|}{ Annual mean } \\
\hline Station & Abbr. & $D L R_{\text {Obs }}^{A l l}$ & $\mathrm{~T}_{\mathrm{s}}$ & $\mathrm{RH}_{\mathrm{S}}$ & PW & SDI & Pyrgeometer \\
\hline Bermuda & BER & 376.5 & 294.4 & 76.5 & 29.7 & 0.65 & PIR \\
\hline Fukuoka & FUA & 357.6 & 291.3 & 67.7 & 28.5 & 0.67 & CG4 \\
\hline Ishigakijima & ISH & 407.2 & 297.8 & 76.9 & 46.0 & 0.72 & CG4 \\
\hline Lindenberg & LIN & 307.1 & 280 & 87.3 & 15.6 & 0.72 & PIR/CG4 \\
\hline Ny-Ålesund & NYA & 255.1 & 269.1 & 73.0 & 6.9 & 0.78 & PIR \\
\hline Sapporo & SAP & 320.9 & 284.2 & 69.7 & 19.1 & 0.68 & CG4 \\
\hline Syowa & SYO & 218.8 & 262.7 & 68.1 & 3.6 & 0.70 & CG4 \\
\hline \multirow[t]{2}{*}{ Tateno } & TAT & 336.6 & 287.5 & 73.7 & 24.0 & 0.61 & CG4 \\
\hline & & {$\left[\mathrm{W} \mathrm{m}^{-2}\right]$} & {$[\mathrm{K}]$} & {$[\%]$} & {$[\mathrm{mm}]$} & {$[0-1]$} & \\
\hline
\end{tabular}

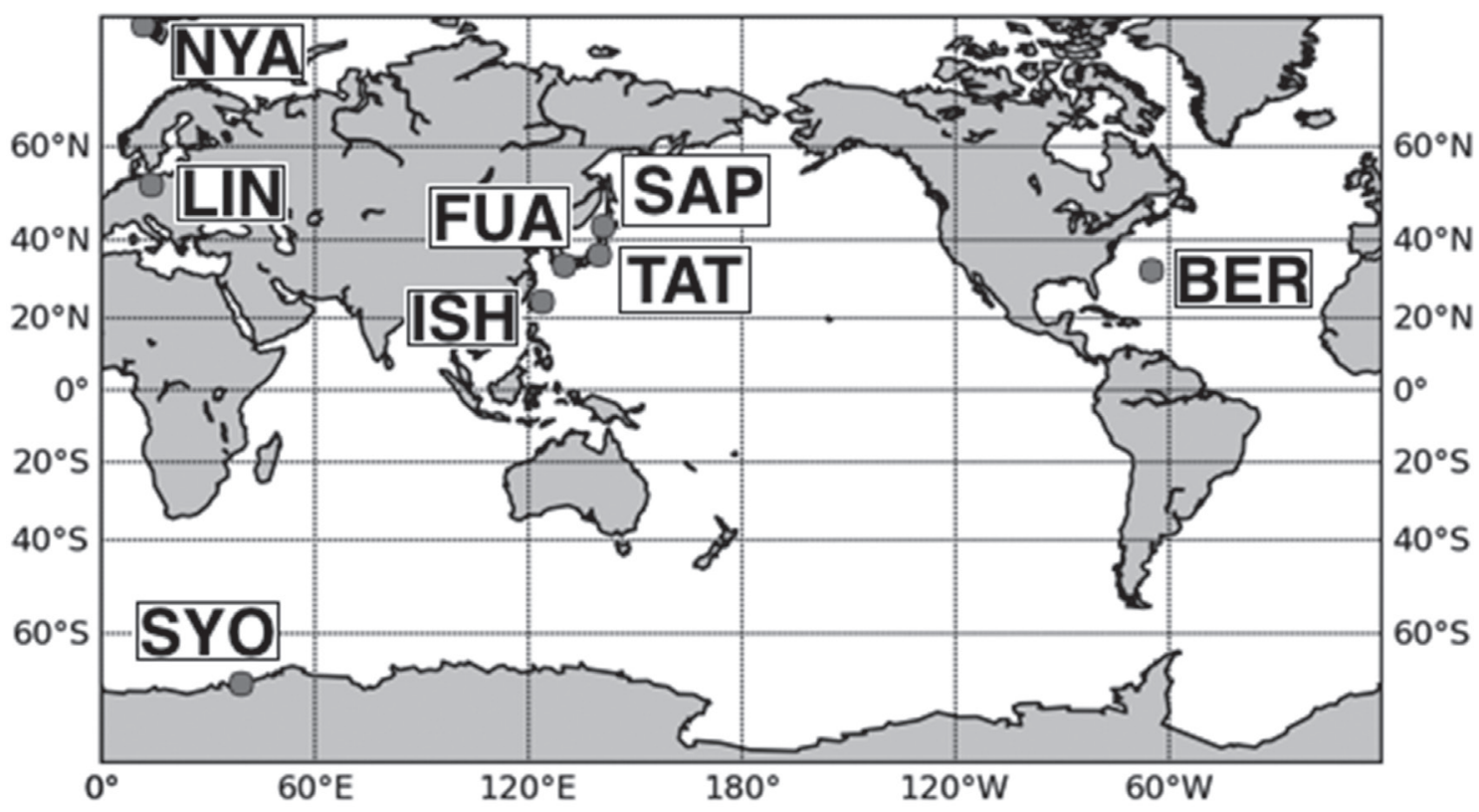

Fig. 1. Observation sites. At these sites, the calculated and observed values show good agreement. 
Table 2. Characteristics of pyrgeometers.

\begin{tabular}{lccc}
\hline & PIR (Eppely) & CG4 (Klpp \& Zonen) & \\
\hline Wavelength & $4 \sim 50$ & $4.5 \sim 42$ & $\mu \mathrm{m}$ \\
Sensitivity & $\sim 5$ & $5 \sim 10$ & $\mu \mathrm{V}\left(\mathrm{W} \mathrm{m}^{-2}\right)^{-1}$ \\
Response Speed & $2(1 / \mathrm{e})$ & $6(63 \%)$ & $\mathrm{sec}$ \\
Temperature Dependability & $<1$ & $<1$ & $\%$ \\
Environmental Temperature & $-20 \sim 40$ & $-40 \sim 80$ & ${ }^{\circ} \mathrm{C}$ \\
\hline
\end{tabular}

Station (SYO), Antarctica), which is the coldest and driest station, are $263 \mathrm{~K}, 4 \mathrm{~mm}$, and $219 \mathrm{~W} \mathrm{~m}^{-2}$, respectively. We categorized the area around stations into three types of regions by annual average PW. Dry regions have annual average PW less than 10 $\mathrm{mm}$; this includes the areas of Ny-Ålesund (NYA) and SYO. Moderate regions have PW values of at least $10 \mathrm{~mm}$ but less than $25 \mathrm{~mm}$, and humid regions have values greater than $25 \mathrm{~mm}$. Lindenberg (LIN), Sapporo (SAP), and Tateno (TAT) are in moderate regions. Fukuoka (FUA), Bermuda (BER), and Ishigakijima (ISH) are in humid regions.

BSRN observation data are separated into subsets. We used 0100 basic observation data ( $D L R_{O b s}^{A l l}$, direct shortwave radiation (DIR), and diffuse shortwave radiation (DIF)), 1000 meteorological data (cloud fraction by human observation and wind direction), and 1100 radiosonde data (vertical distributions of air temperature and relative humidity). To evaluate cloud amount, we used the shortwave diffusivity index (SDI; Long and Ackerman 2000) because of limits in the number and accuracy of cloud amount observations by human observation. SDI is defined by the formula

$$
S D I=\frac{D I F}{D I R \times \mu+D I F},
$$

where $\mu$ is the cosine of the solar zenith angle. We used only daytime data in estimating SDI. Cloud fraction from human observation is used for comparing calculations and observations only.

$D L R_{\text {Obs }}^{A l l}$ was observed using CG4 (Kipp \& Zonen) or PIR (Eppley) pyrgeometers. Table 2 shows the characteristics of the pyrgeometers. BSRN station radiation observations have a sensitivity of $1 \mathrm{~Hz}$ and are taken on average once per minute. FUA, ISH, SAP, SYO, and TAT use CG4 pyrgeometers; BER and NYA use PIR pyrgeometers; LIN uses both types. The performance differs between PIR and CG4 pyrgeometers in terms of some properties such as the wavelength range. Payne (2004) compared these two types of pyrgeometers in 2002 for nine months in
Massachusetts and found that the difference in DLR measurements was less than $5 \mathrm{~W} \mathrm{~m}^{-2}$ in a 1-minute average over the observation period. In this study, the DLR observations made by CG4 pyrgeometers are not distinguished from those made by PIR pyrgeometers. To limit the effects of small perturbations and instrumental error, hourly averages are used for radiation data.

Ceilometer and lidar are useful instruments for detecting clouds. Among the eight BSRN stations, LIN and NYA both have an LD-40 Ceilometer (Vaisala) by which they observe cloud base height $(\mathrm{CBH})$; the measurement wavelength is $855 \mathrm{~nm}$ and the temporal resolution is $15 \mathrm{~s}$. SAP and TAT each have a Mie lidar from the National Institute for Environmental Studies (NIES). The Mie lidar observes the attenuated backscattering coefficient $(\mathrm{ABC})$ using 532-nm- and 1064-nm-wavelength lasers every 15 min. CBH is estimated from the 1064-nm-wavelength signal (Shimizu et al. 2010). CBH is estimated as the height at which the increment of the $\mathrm{ABC}$ for 1064 $\mathrm{nm}$ is larger than $4 \times 10^{8} \mathrm{sr}^{-1} \mathrm{~m}^{-1}$. The height resolution of the $\mathrm{ABC}$ is $6 \mathrm{~m}$; however, the height resolution of $\mathrm{CBH}$ is $30 \mathrm{~m}$ because five data segments are averaged to increase the signal-to-noise ratio. The accuracy of cloud detection in the lower atmosphere is unreliable, and thus Mie lidar does not provide $\mathrm{CBH}$ below an altitude of $120 \mathrm{~m}$.

Table 3 describes the two instruments. The wavelength and vertical resolution differ between ceilometer and lidar measurements. Here, low clouds are the main target because high clouds are not easily detected by in situ observations, and the difference in accuracy between lidar and ceilometer detection of low clouds is small. $\mathrm{CBH}$ is limited to the range between 150 and $10,000 \mathrm{~m}$ to account for the lidar measurement range and the poor detection accuracy of thin high-altitude clouds.

\subsection{Calculation scheme}

To calculate $D L R_{\text {Cal }}^{\text {Clear }}$, we used mstrnX (Sekiguchi and Nakajima 2008), which is a two-stream radiative 
Table 3. Characteristics of instruments used for observing $\mathrm{CBH}$.

\begin{tabular}{lccc}
\hline & LD-40 (Vaisala) & Mie lidar (NIES) & \\
\hline Wavelength & 855 & 1064 & {$[\mathrm{~nm}]$} \\
Mesurement range & $8-13000$ & $150-18000$ & {$[\mathrm{~m}]$} \\
Vertical resolution & 8 & 30 & {$[\mathrm{~m}]$} \\
Temporal resolution & $15 \mathrm{sec}$. & $15 \mathrm{~min}$. & \\
\hline
\end{tabular}

transfer model. In this study, mstrnX had 370 layers with thicknesses of $1 \mathrm{~km}$ from the TOA to $30 \mathrm{~km}$ and of $100 \mathrm{~m}$ from $30 \mathrm{~km}$ to the surface. MstrnX calculates $D L R_{\text {Cal }}^{\text {Clear }}$ from the vertical distribution of air temperature and concentration of greenhouse gases (GHGs). The concentration of GHGs other than $\mathrm{CO}_{2}$ was taken from the 1976 U.S. Standard Atmosphere, whereas the concentration of $\mathrm{CO}_{2}$ in the troposphere was taken from observations (Keeling et al. 2008). The $\mathrm{CO}_{2}$ concentration varies by season and location. Although this horizontal distribution reaches near 10 ppmv, the effect on $D L R_{\text {Cal }}^{\text {Clear }}$ calculated by mstrnX is less than $0.2 \mathrm{~W} \mathrm{~m}^{-2}$, which is negligible. The vertical distributions of air temperature and water vapor were obtained from radiosonde observations.

For the eight stations, $D L R_{\text {Cal }}^{\text {Clear }}$ shows good agreement with $D L R_{O b s}^{A l l}$ under the clear-sky condition. Figure 2 shows the comparison between calculated and observed values under clear-sky conditions. The clear-sky condition has values of SDI less than 0.3 and a cloud fraction of 0 oktas by human observation. The data give the following: calculation observation $=-2.84 \pm 6.16 \mathrm{~W} \mathrm{~m}^{-2}$ with correlation coefficient $r=0.996$. Therefore, it is reasonable to estimate cloud effect. We calculated CRF and CRC from data given by mstrnX calculations under the clear-sky condition and by observations under the all-sky condition.

To estimate the cloud effect on DLR at the surface under various conditions, we took SDI, PW, and $\mathrm{CBH}$ as parameters. SDI was estimated as the ratio of the sum of direct and diffuse shortwave downward radiation to the diffuse shortwave downward radiation; a value of 0 indicates a completely clear sky and 1 indicates a completely cloud-covered sky (SDI is typically larger than 0 because of aerosol and gases diffusion). PW was calculated from radiosonde observations of the vertical profile of water vapor, and $\mathrm{CBH}$ was estimated using the ceilometer and the NIES Mie lidar.

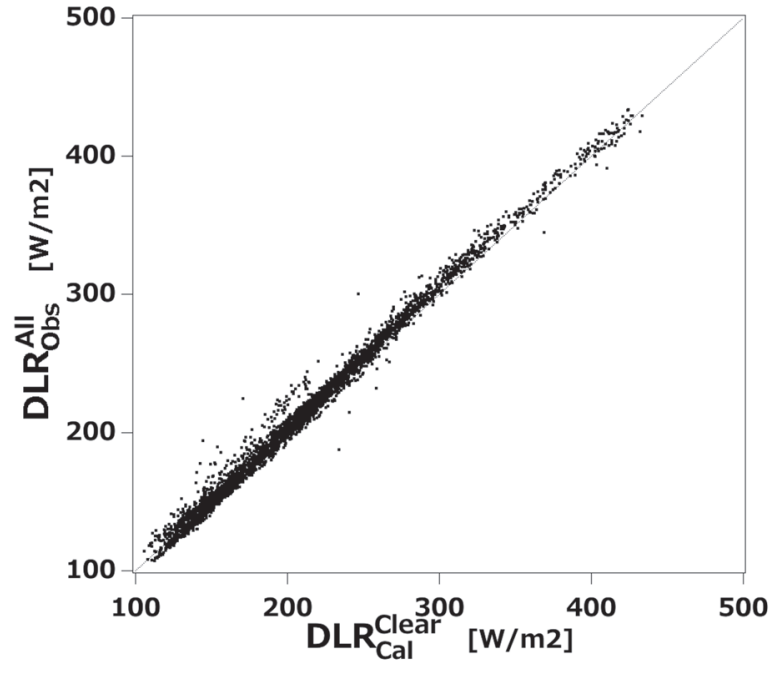

Fig. 2. Comparison between $D L R_{\text {Cal }}^{\text {Clear }}$ and $D L R_{O b s}^{A l l}$ under the clear-sky condition. In the clear-sky condition, SDI $<0.3$ and the cloud amount recorded by human observation is 0 okta.

\section{Results and Discussion}

\subsection{Impacts of SDI and $P W$}

Figure 3 illustrates the relationships at the eight observation stations between SDI and other measures: CRF, average $D L R_{O b s}^{A l l}$ (average of \pm 0.05 of SDI every 0.1 , and CRC. CRF and CRC exhibit large variability, from -21 to $92 \mathrm{~W} \mathrm{~m}^{-2}$ and from $-6 \%$ to 38 $\%$, respectively. Most scatterplots in Fig. 3 are from -10 to $80 \mathrm{~W} \mathrm{~m}^{-2}$ and from $-5 \%$ to $35 \%$. The average cloud effect increases both absolutely and relatively with increasing SDI.

PW is an important factor in evaluating cloud effect because water vapor is a strong absorber and emitter of longwave radiation. We classified each observation site as having one of three humidity conditions according to its PW: dry (annual mean $\mathrm{PW}<10$ $\mathrm{mm}$ ), moderate $(10 \leq \mathrm{PW}<25 \mathrm{~mm}$ ), or humid (PW $\geq 25 \mathrm{~mm}$ ). Figure 4 shows the relationship for each 


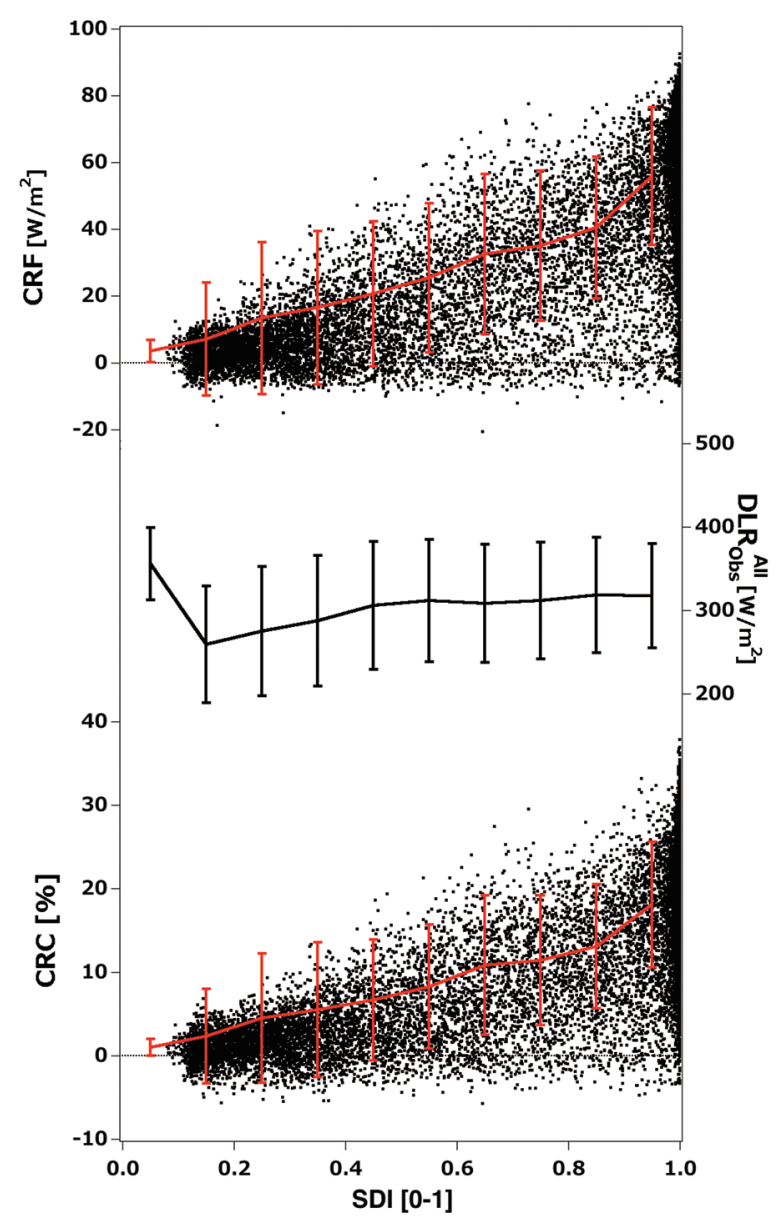

Fig. 3. Relationships between SDI and CRF (top), average (center), and CRC (bottom). Red curves show the mean with error bars (1 standard deviation).

humidity condition between SDI and other measures: CRF, average $D L R_{O b s}^{A l l}$, and CRC. When SDI is less than 0.6, CRF is unaffected by the humidity condition. A comparison of the average CRF for dry and humid conditions when SDI was between 0.9 and 1.0 showed a difference of about $20 \mathrm{~W} \mathrm{~m}^{-2}$. A comparison of $D L R_{O b s}^{A l l}$ under the three humidity conditions shows a difference of $40-60 \mathrm{~W} \mathrm{~m}^{-2}$, which means that the relative contributions of cloud differ significantly by humidity. The standard deviation of CRC is larger in the dry condition than in the humid condition. Under the dry condition, the average $\mathrm{CRC}$ ranges from about $0 \%$ to more than $20 \%$. In general, the average CRC decreases with increasing PW. The effect of cloud is large under the dry condition because the effect of water vapor is small. Accordingly, differences in

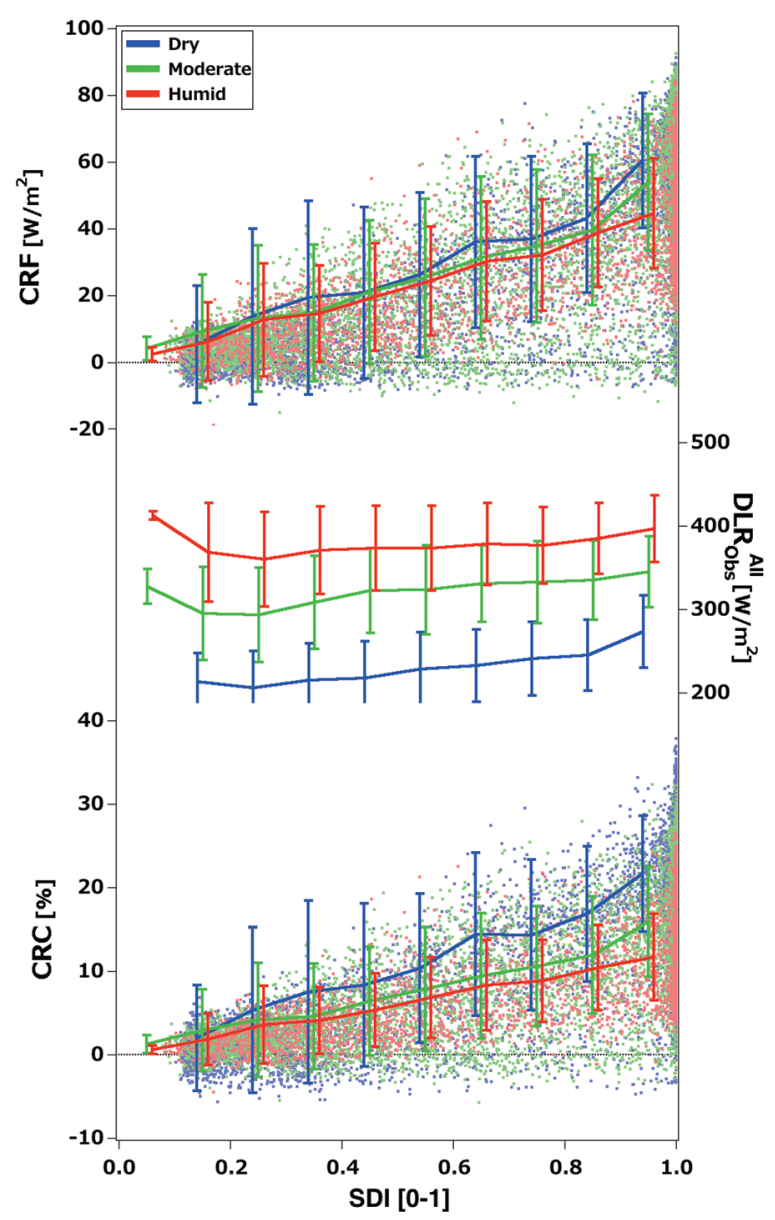

Fig. 4. Relationships between SDI and CRF (top), average (center), and CRC (bottom). Red, green, and blue curves show means for humid (annual mean PW at least $25 \mathrm{~mm}$ ), moderate (annual mean PW less than $25 \mathrm{~mm}$ and more than 10 $\mathrm{mm}$ ), and dry conditions (annual mean PW less than $10 \mathrm{~mm}$ ), respectively.

cloud physical characteristics (e.g., cloud thickness, altitude, and amount) are more important under the dry condition than under the humid condition, which causes CRC to exhibit large variability.

Figure 5 shows the relationship that $\mathrm{PW}$ has to CRF, DLR All Obs and CRC. Stephens et al. (2012; hereafter S12) showed the relationship between CRF and column water vapor by using A-Train satellite data. The temporal and spatial resolutions of data were $3 \mathrm{~h}$ and $1^{\circ} \times 1^{\circ}$, respectively; these resolutions are much coarser than those of the data used in the present study ( $1 \mathrm{~h}$ and 1 pixel). Our results show good correspondence with those of S12 overall. The three following 


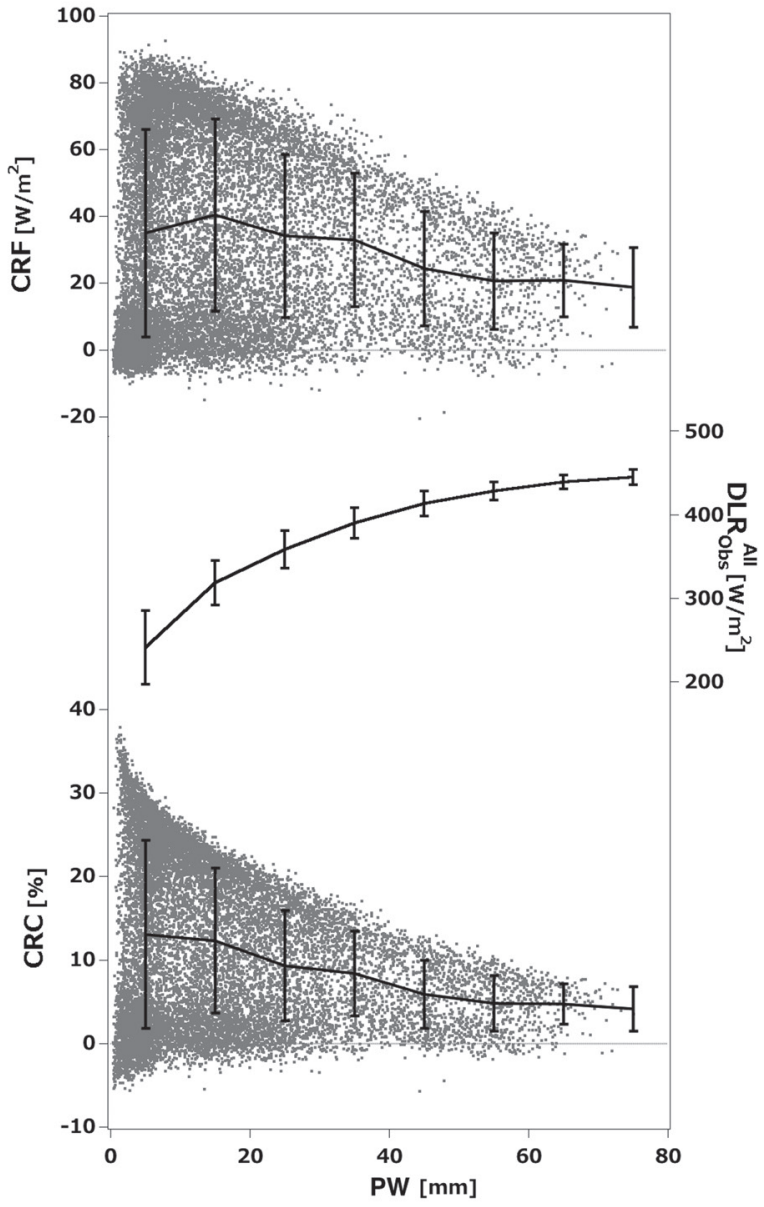

Fig. 5. Relationships between PW and CRF (top), average (center), and CRC (bottom). Black curves show the mean with error bars (1 standard deviation).

relationships between CRF and column water vapor were found in S12. In areas where the column water vapor amount is about $0-10 \mathrm{~mm}, \mathrm{CRF}$ increases with increasing water vapor amount. In areas where the water vapor amount is about $10-40 \mathrm{~mm}, \mathrm{CRF}$ is inversely proportional to the amount of water vapor. Under very humid conditions, in which the water vapor amount is larger than $40 \mathrm{~mm}, \mathrm{CRF}$ is insensitive to changes in water vapor amount. However, S12 did not show details of the variation in cloud effect. There are two clear differences between the present study and that of S12. One difference is that the present study shows a high incidence of a large negative cloud effect in very cold and dry regions. The other difference is the wider range for CRF in the present study than in $\mathrm{S} 12$.
Cloud effect sometimes takes a negative value. In an Arctic study, Shupe and Intrieri (2003) suggested that negative values for cloud effect can be attributed to model or observation errors under the clear-sky condition. However, negative cloud effect values show a tendency to concentrate in the low-PW region in the scatterplots, suggesting that there may be another reason for the negative values. Figure 6 shows the vertical profiles of air temperature and relative humidity on a day when CRC was strongly negative (less than $-3 \%$ ) and on a following day when CRC was very large (more than $20 \%$ ) at SYO, which belongs to a dry region in this study. A common feature of Figs. 6a, 6b, and $6 \mathrm{~d}$ is the presence of a strong temperature inversion near the surface when CRC was less than $-3 \%$; panel $\mathrm{c}$ also shows a weak inversion. Figure 7 shows the relationship between PW and CRF, partitioned on the presence of a temperature inversion. In the figure, the orange plot and curve show data for which a temperature inversion exists below $3000 \mathrm{~m}$. Data for which no temperature inversion exists are plotted in black. The two conditions show similar tendencies. However, under the dry condition ( $\mathrm{PW}$ is smaller than $10 \mathrm{~mm}$ ), the average CRF with temperature inversion is smaller than that with no inversion, although there is large variation in the values.

According to the Stefan-Boltzmann law, blackbody radiative emission is proportional to the fourth power of absolute temperature. Downward longwave flux, empirically calculated under the clear-sky condition, exhibits more dependence on air temperature than is accounted for by this law; for example, Swinbank (1963) suggests that the flux is proportional to the sixth power of surface air temperature. The reason for the strong temperature effect is that an increase in the air temperature causes an increase in water vapor pressure at the surface and thus an exponential increase in the column water vapor amount (Deacon 1970). King (1996) indicated that empirical parameterization at the Arctic yielded downward longwave flux at the surface proportional to the fourth power of air temperature or to the sixth power of cloud-base temperature. In polar regions, strong temperature inversions appear frequently because of the ice-covered surface. The inversion layer is strongest in winter, when it is sometimes warmer than the surface air by $30 \mathrm{~K}$, and affects the radiation budget (Phillipot and Zillman 1970; Stone 1993; Curry et al. 1996). The frequent occurrence of negative CRC values in the present study is attributed to the absorption of radiation from an upper-air temperature inversion due 

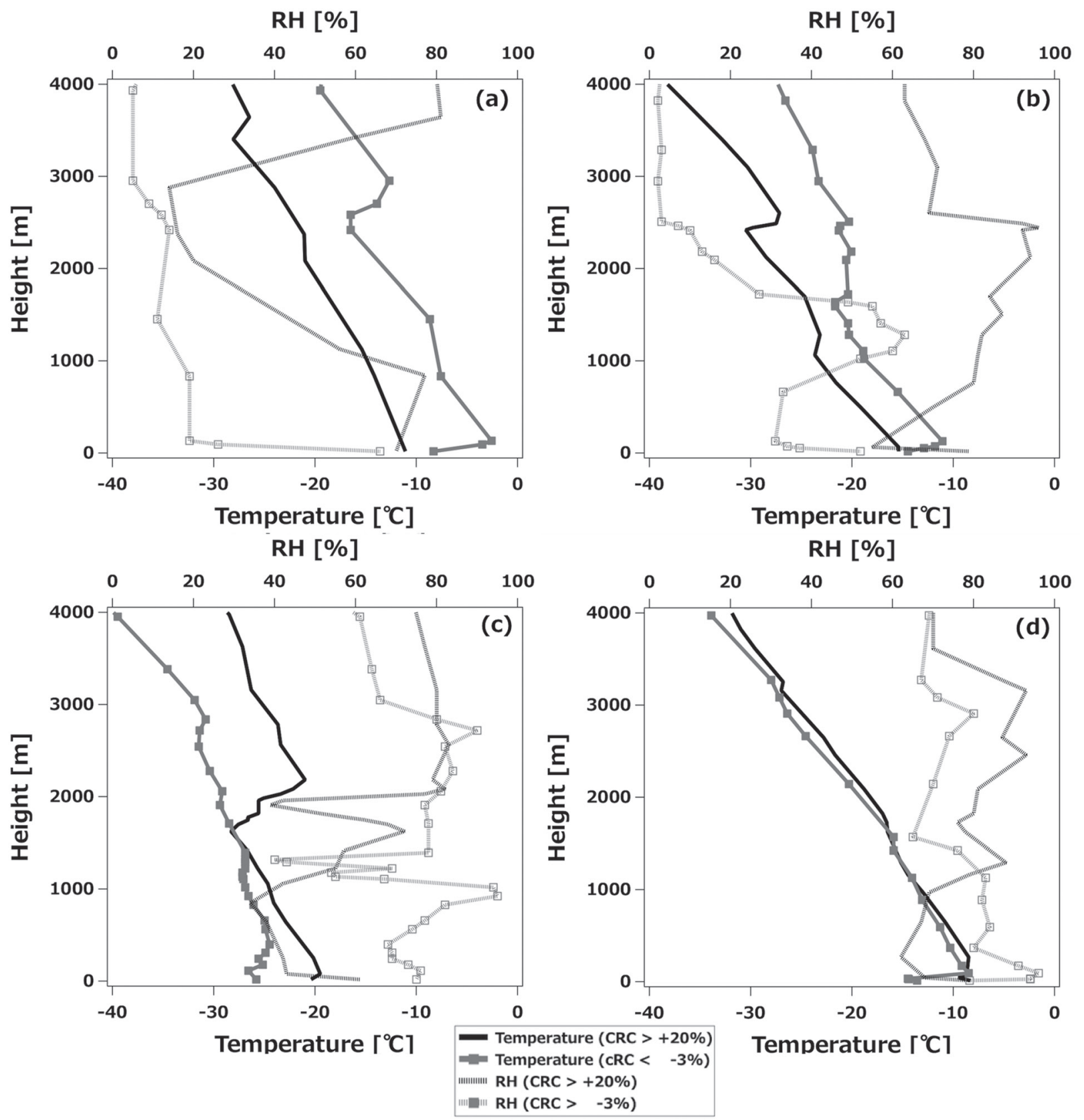

Fig. 6. Vertical profiles of air temperature and relative humidity on days when CRC was smaller than $-3 \%$ (dashed) and when CRC was larger than $20 \%$ (continuous) at SYO (located in a dry region). Continuous (resp. dashed) measurements are from a) 10 Nov 2011, 00 UTC (11 Nov 2001, 00 UTC); b) 22 Jul 2006, 12 UTC (7 Jun 2006, 00 UTC); c) 27 Jul 2006, 12 UTC (23 Jul 2006, 12 UTC); and d) 22 May 2009, 00 UTC (23 May 2009, 12 UTC).

to clouds.

Figure 8 shows the relationship that $\mathrm{PW}$ has to $\mathrm{CRF}$ and CRC under nearly clear (SDI $<0.5)$, cloudy $(0.5 \leq$ SDI $<0.9)$, and overcast $(\mathrm{SDI} \geq 0.9)$ condi- tions. Under nearly clear conditions, the average CRC (average of $\pm 5 \mathrm{~mm}$ of PW every $10 \mathrm{~mm}$ ) is near $0 \%$, and the scatterplot shows low dispersion, except in dry regions $(\mathrm{PW}<10 \mathrm{~mm})$. In contrast, average $\mathrm{CRC}$ 


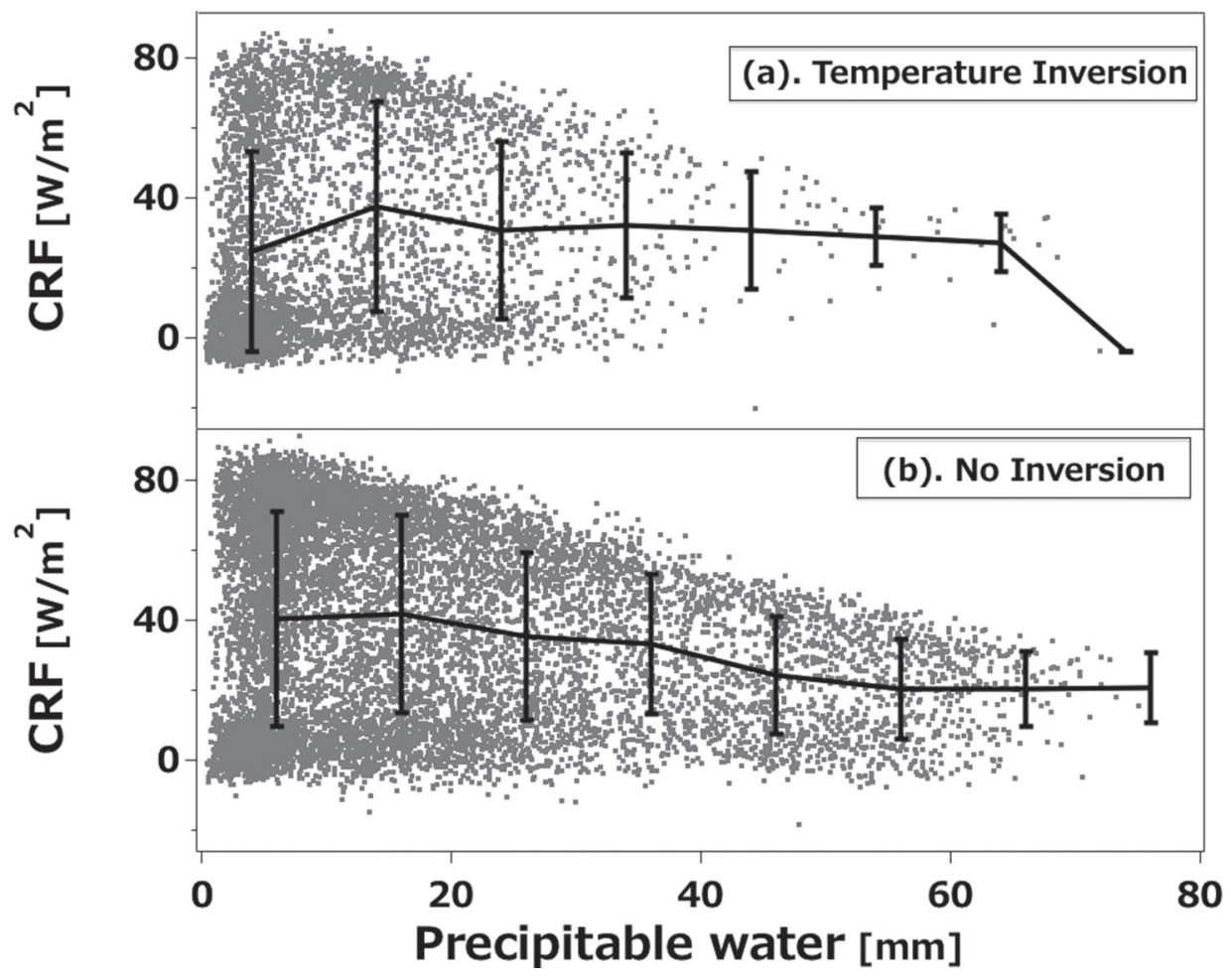

Fig. 7. Relationship between PW and CRF. Each dot represents a data point and black line shows the mean with error bars (1 standard deviation). (a) Days with temperature inversion below $3000 \mathrm{~m}$. (b) Days with no temperature inversion.

under overcast conditions is large and roughly inverse to PW. Under cloudy conditions, CRC lies between these two extremes; the scatterplot shows a large dispersion from dry to wet climates.

The present study and S12 differ in the distribution of data. While S12 shows CRF scattered from about $-10 \mathrm{~W} \mathrm{~m}^{-2}$ to about $70 \mathrm{~W} \mathrm{~m}^{-2}$, this study shows CRF scattered from about -20 to about $90 \mathrm{~W} \mathrm{~m}^{-2}$. In addition, S12 found that CRF was concentrated in a narrow curved band. In contrast, this study finds CRF scattered widely, rather than concentrated. However, in Fig. 8, CRF under the overcast condition is distributed in a way similar to that found in S12, although the maximum value is larger here than in S12. This indicates that the A-Train product cannot detect clouds under nearly clear conditions and therefore misses the effect of small clouds.

DLR is susceptible to local conditions. The small CRC when PW is $10 \mathrm{~mm}$, reported by $\mathrm{S} 12$, is ascribed to the difficulty in observing the near-surface atmosphere using a satellite when cloud cover is present; this difficulty is because of the coarse spatial and temporal resolutions. Yamamoto and Sasamori (1954) showed that $80 \%$ of DLR is emitted from water vapor at pressures below $900 \mathrm{hPa}$; this finding was based on radiation chart data for Sendai, Japan. Philipona et al. (2004) calculated downward longwave flux using the MODTRAN software package (Version 4.2; Berk et al. 1987) for data from Payerne, Switzerland, and found that more than $90 \%$ of DLR is emitted from atmosphere below $1000 \mathrm{~m} ; 39 \%$ is emitted from atmosphere below $10 \mathrm{~m}$. It is difficult for satellite observations to retrieve near-surface water vapor distribution, which has a disproportionately large influence on DLR.

\subsection{Impact of cloud base height}

The LIN and NYA stations measure CBH using an LD-40 ceilometer. The SAP and TAT stations use Mie lidar instruments to measure $\mathrm{CBH}$; these sites are near each other but have different climates because of monsoon effects. In this section, we focus on data from these four stations to estimate the effect that $\mathrm{CBH}$ has on the cloud radiative effect. Because 

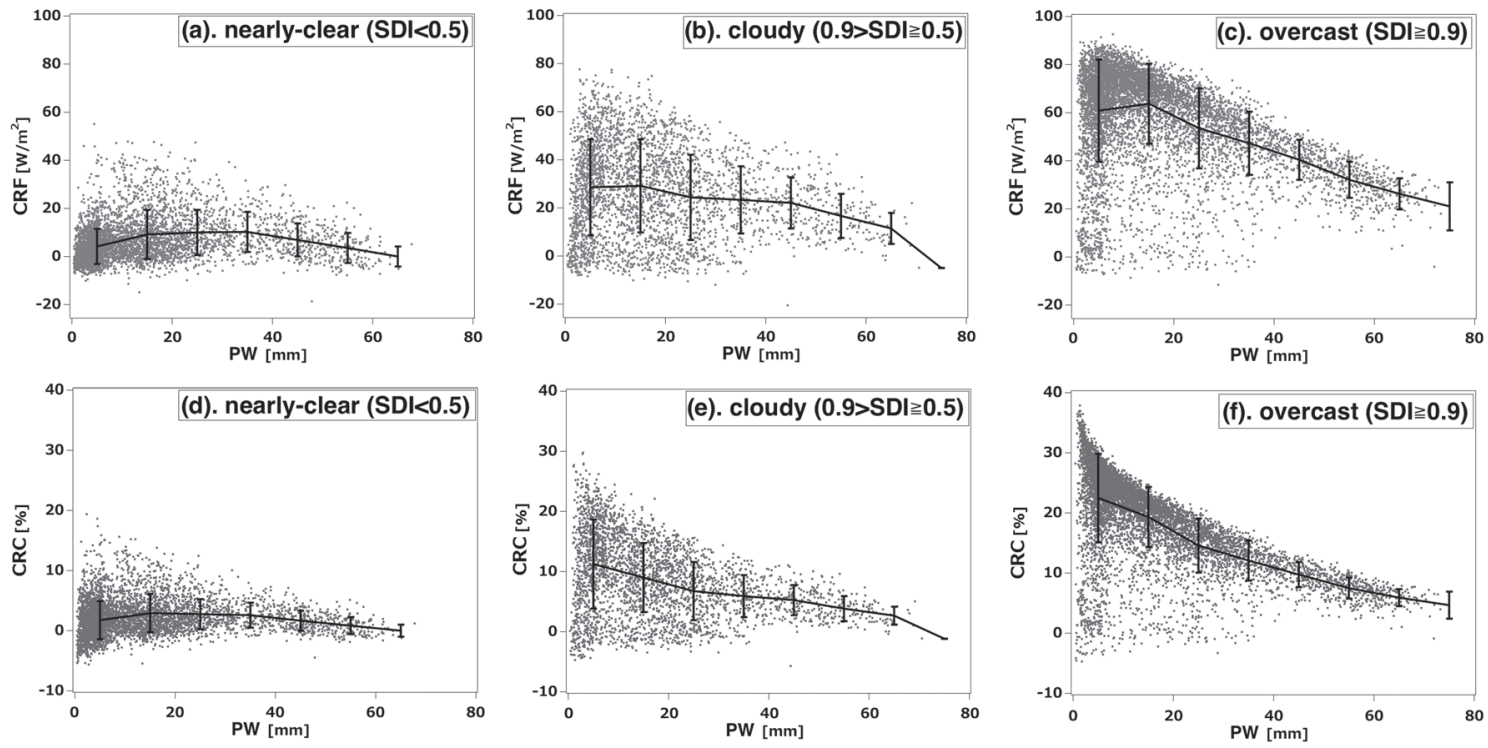

Fig. 8. Relationships between PW and CRF (upper panels) and CRC (lower panels) under (a, d) nearly clear (SDI $<0.5)$, (b, e) cloudy $(0.9>$ SDI $\geq 0.5)$, and (c, f) overcast (SDI $\geq 0.9)$ conditions.

estimated errors in $\mathrm{CBH}$ are large for high-altitude clouds, data showing $\mathrm{CBH}$ more than $10 \mathrm{~km}$ are discarded.

Figure 9 shows the relationship that $\mathrm{CBH}$ has to CRF, DLR Obss , and CRC at the four sites. CRF and CRC (averaged per $1000 \mathrm{~m}$ of height) show generally inverse correlations with $\mathrm{CBH}$, as expected. Cloud effect varies widely due to other forcing parameters such as SDI or PW. For low clouds $(\mathrm{CBH}<2000$ $\mathrm{m})$, the cloud effect is very different among the four sites. At TAT only, the cloud effect increases with increasing CBH below $2000 \mathrm{~m}$. The larger the annual average of $\mathrm{PW}$, the smaller the average of cloud effect.

Figure 10 shows CRF dependence on $\mathrm{CBH}$ under clear (SDI $<0.5$; a), cloudy $(0.5 \leq \mathrm{SDI}<0.9$; b), and overcast (SDI $\geq 0.9 ; c)$ conditions. Under nearly clear conditions, the effect of $\mathrm{CBH}$ is very small, and the average CRF is about $2-20 \mathrm{~W} \mathrm{~m}^{-2}$. Increasing cloud amounts leads to wide dispersion in CRF. Under cloudy and overcast conditions, CRF decreases with increasing $\mathrm{CBH}$ from the surface to $10 \mathrm{~km}$. Very high clouds are difficult to detect with lidar because of attenuation of the laser, and therefore the standard deviation of CRC at $\mathrm{CBH}$ above $5 \mathrm{~km}$ is very large. Under nearly clear conditions, CRF shows little change from changes in $\mathrm{CBH}$, and the difference among sites is also small. At TAT, under cloudy and overcast conditions, average CRF increases with increasing $\mathrm{CBH}$ when $\mathrm{CBH}$ is less than $2 \mathrm{~km}$; this is the same as under the all-sky condition, which is contrary to the expectation that CRF should decrease with decreasing $\mathrm{CBH}$.

Figure 11 shows the joint frequencies of annual mean and seasonal variation of the relationship between $\mathrm{CBH}$ and CRF at LIN, NYA, SAP, and TAT. When CBH is low, low clouds are dominant at all stations for annual mean (Fig. 11-1). Large CRF occurs frequently at LIN and NYA. When high CRF and low $\mathrm{CBH}$ have a high joint frequency, an inverse relationship between $\mathrm{CBH}$ and $\mathrm{CRF}$ is reasonable because of the gradual decrease in temperature with increasing altitude. In contrast, the CRF annual mean is often small at SAP and TAT stations. The low joint frequency of high CRF and low $\mathrm{CBH}$ weakens the inverse relationship between $\mathrm{CBH}$ and $\mathrm{CRF}$, resulting in a directly proportional relationship.

Figures 11-2 (spring), 11-3 (summer), 11-4 (autumn), and 11-5 (winter) show seasonal variations in the relationship between $\mathrm{CBH}$ and CRF; the data for NYA in winter is excluded because radiosonde observations are not performed there during the daytime in winter. Seasonal variations at LIN and NYA are small. CBH below $2000 \mathrm{~m}$ occurs frequently at LIN throughout the year. When low clouds are present, CRF exhibits bimodal characteristics; CRF occurs frequently at values greater than $60 \mathrm{~W} \mathrm{~m}^{-2}$ and at small values around $0 \mathrm{~W} \mathrm{~m}^{-2}$. The tendencies at 


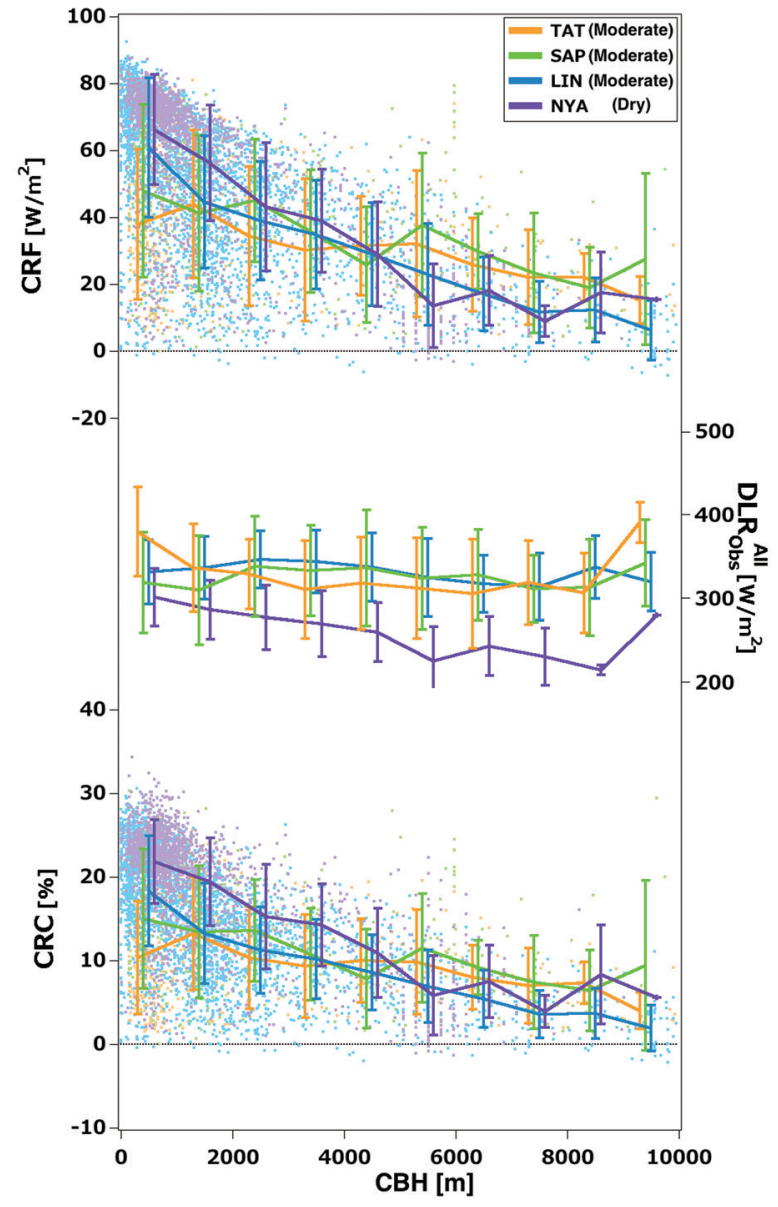

Fig. 9. Relationships between $\mathrm{CBH}$ and $\mathrm{CRF}$ (top), average (center), and CRC (bottom) at four sites. Observations are grouped by color: orange (TAT), green (SAP), blue (LIN), and purple (NYA). TAT, SAP, and LIN sites are in moderate humidity regions. NYA is in a dry region.

NYA are generally similar to those at LIN. The incidence of low clouds is high and CRF exhibits bimodal characteristics. NYA differs from LIN with respect to high clouds with $\mathrm{CBH}$ around $5000 \mathrm{~m}$, which occur slightly more often at LIN.

At SAP and TAT, the joint distribution of $\mathrm{CBH}$ and CRF varies dramatically by season. High clouds are more frequent than low clouds during spring and summer at SAP and during autumn at TAT. Although these high and cold clouds are commonly thin, with small CRF, the incidence of CRF larger than $30 \mathrm{~W} \mathrm{~m}^{-2}$ is high for spring and summer at SAP. During autumn and winter at SAP, low clouds occur frequently, but the distribution of CRF differs from
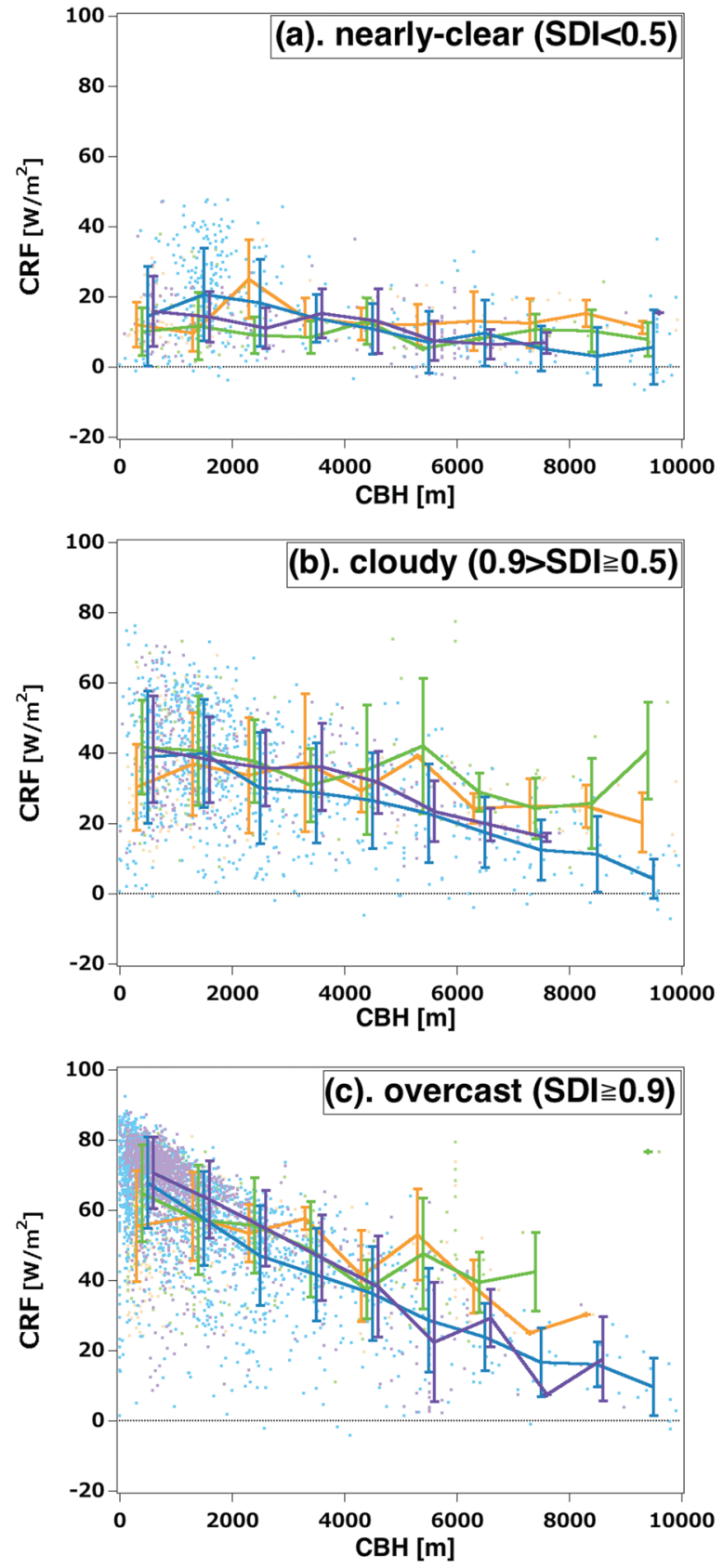

Fig. 10. Relationships between $\mathrm{CBH}$ and $\mathrm{CRF}$ under (a) nearly clear (SDI $<0.5)$, (b) cloudy $(0.5$ $\leq \mathrm{SDI}<0.9)$, and $(\mathrm{c})$ overcast $(\mathrm{SDI} \geq 0.9)$ conditions at four sites. Orange, green, and blue colors represent TAT, SAP, and LIN data, respectively.

that observed during spring and summer. The incidences of low clouds with small CRF and low clouds with high CRF are approximately the same. 

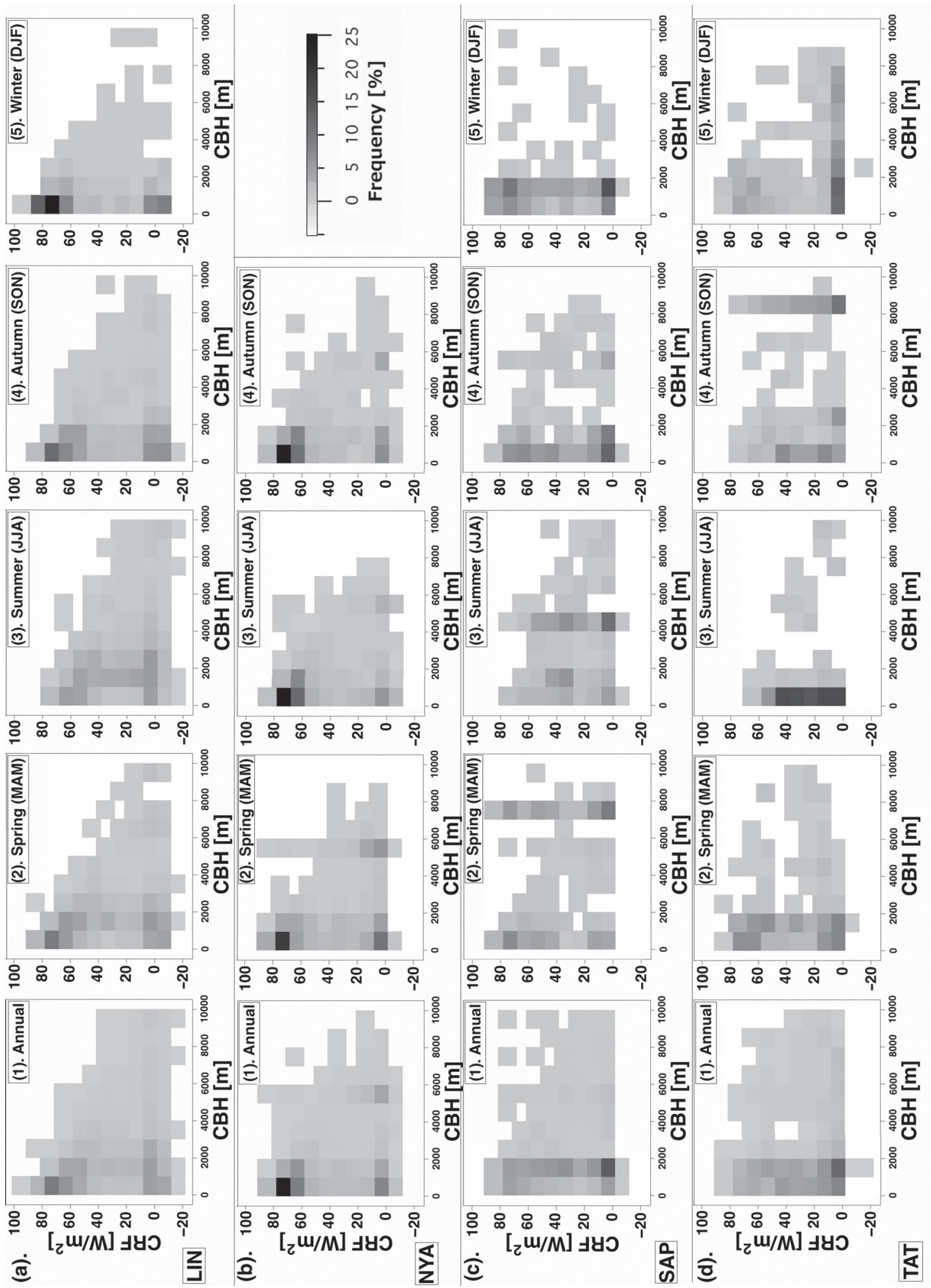

Fig. 11. Joint frequencies between CBH and CRF at (a) LIN, (b) NYA, (c) SAP, and (d) TAT. Periods shown are (1) annual, (2) spring (March to May), (3) summer (June to August), (4) autumn (September to November), and (5) winter (December to February). Frequency is indicated by brightness, with black indicating the highest frequency. 
The relationship between $\mathrm{CBH}$ and $\mathrm{CRF}$ at TAT for summer and winter is quite different from the other stations and seasons. During summer, near-surface clouds $(\mathrm{CBH}<1000 \mathrm{~m})$ dominate, and it is hard to detect clouds at other altitudes. The incidence of low-altitude clouds is high for CRF from near 0 to $60 \mathrm{~W} \mathrm{~m}^{-2}$. The incidence of low- or middle-altitude clouds is high during winter. In Fig. 9, the annual average of CRF at TAT increases with increasing $\mathrm{CBH}$ when $\mathrm{CBH}$ is less than $2 \mathrm{~km}$. This is attributed to the unusual relationship between $\mathrm{CBH}$ and $\mathrm{CRF}$ during summer and winter at TAT.

A positive correlation exists between $\mathrm{CBH}$ and CRF at TAT for very low clouds. Because low clouds can be treated as an optically thick black body, the positive correlation is not attributed to the effect of cloud properties (e.g., cloud optical thickness or liquid water path), but instead to atmospheric moisture conditions. Figure 12 shows the joint frequencies between $\mathrm{CBH}$ and $\mathrm{PW}$ at the four stations for annual averages (Fig. 12-1) and by season (Figs. 12-2, 12-3, 12-4, and 12-5 correspond to spring, summer, autumn, and winter, respectively).

At LIN, SAP, and TAT, clouds with CBH less than $2000 \mathrm{~m}$ occur more frequently than any other type. Only NYA has high incidences of both low and high clouds. Among low clouds, $0-1000 \mathrm{~m}$ clouds are more frequent than 1000-2000 m clouds at LIN and NYA; $1000-2000 \mathrm{~m}$ cloud is more frequent than $0-1000 \mathrm{~m}$ cloud at SAP and TAT. This difference may account for the difference in cloud height seasonal characteristics among stations.

Although a high incidence of only low clouds is obtained for all seasons at LIN, the frequency distributions can be classified into one of two types. During autumn and winter, the CBH below $1000 \mathrm{~m}$ dominates. Compared with near-surface clouds, $\mathrm{CBH}$ in the 1000-2000 $\mathrm{m}$ range is more frequent during spring and summer.

At NYA, the relationship between PW and CBH is consistent throughout the year: quite low clouds occur frequently; during spring and autumn, high clouds with small PW occur slightly more often, as expected from the relationship between CRF and CBH.

At SAP, the joint frequency between $\mathrm{PW}$ and $\mathrm{CBH}$ indicates large seasonal variations. Middle- and high-altitude clouds are found frequently in spring and summer, similar to that observed at NYA during spring and autumn. In summer, high clouds appear more frequently than low clouds. During autumn, low-altitude clouds appear during dry conditions; this is similar to the pattern at LIN. In winter, most clouds detected occur below 2,000 $\mathrm{m}$ and under quite dry conditions.

At TAT, the joint frequency between $\mathrm{CBH}$ and PW shows large seasonal variations. During spring, the incidence of low clouds is high, similar to those observed in all seasons at LIN and in autumn at SAP. In summer, the incidence of near-surface clouds is high for PW from $20 \mathrm{~mm}$ to $60 \mathrm{~mm}$. An incidence peak is attained under wet conditions. Both high and low clouds occur frequently at TAT during autumn, similar to that at NYA for spring and autumn and SAP for spring and summer. When high clouds are present, $\mathrm{PW}$ is lower than when low clouds are present. One aspect of the joint frequency between $\mathrm{CBH}$ and $\mathrm{PW}$ at TAT is unusual for winter: although low clouds and low PW frequently co-occur at other stations and seasons, clouds of all heights frequently occur under dry conditions at TAT.

Because TAT is located on the Pacific Ocean side of Japan and is affected by the East Asian monsoon, the wind direction changes with the season and determines atmospheric conditions and cloud characteristics (Jhun and Lee 2004; Hirano and Matsumoto 2010; Wang and Ho 2002). Figure 13 shows the relationship between $\mathrm{CBH}$ and surface wind direction at TAT for summer and winter from radiosonde observation data. During summer, the monsoon forms the Baiu Front, which causes heavy clouds and frequent rainfall on the Pacific Ocean side of the island, where TAT is situated. Figure 13a shows frequent northeastern and southern winds; however, near-surface clouds occur frequently regardless of wind direction.

In contrast to summer, the winter monsoon season causes heavy snowfall on the Japan Sea side of Japan, while the Pacific Ocean side of Japan is dry with low precipitation; this occurs because the mountains that extend from the north to the south at the center of the Honshu island of Japan block humid winds. Figure $13 \mathrm{~b}$ shows that two wind directions frequently co-occur with clouds. When the wind direction is northern or northeastern, only low clouds occur frequently; when the wind direction is western or northwestern, clouds at all heights occur frequently. These results indicate that wind direction corresponds to atmospheric conditions and affects the incidence of clouds. This relationship is particularly strong during the winter season.

\section{Summary}

We estimated the effect of clouds on DLR at the surface by using observed DLR with absolute (CRF) and relative (CRC) values under the all-sky condi- 

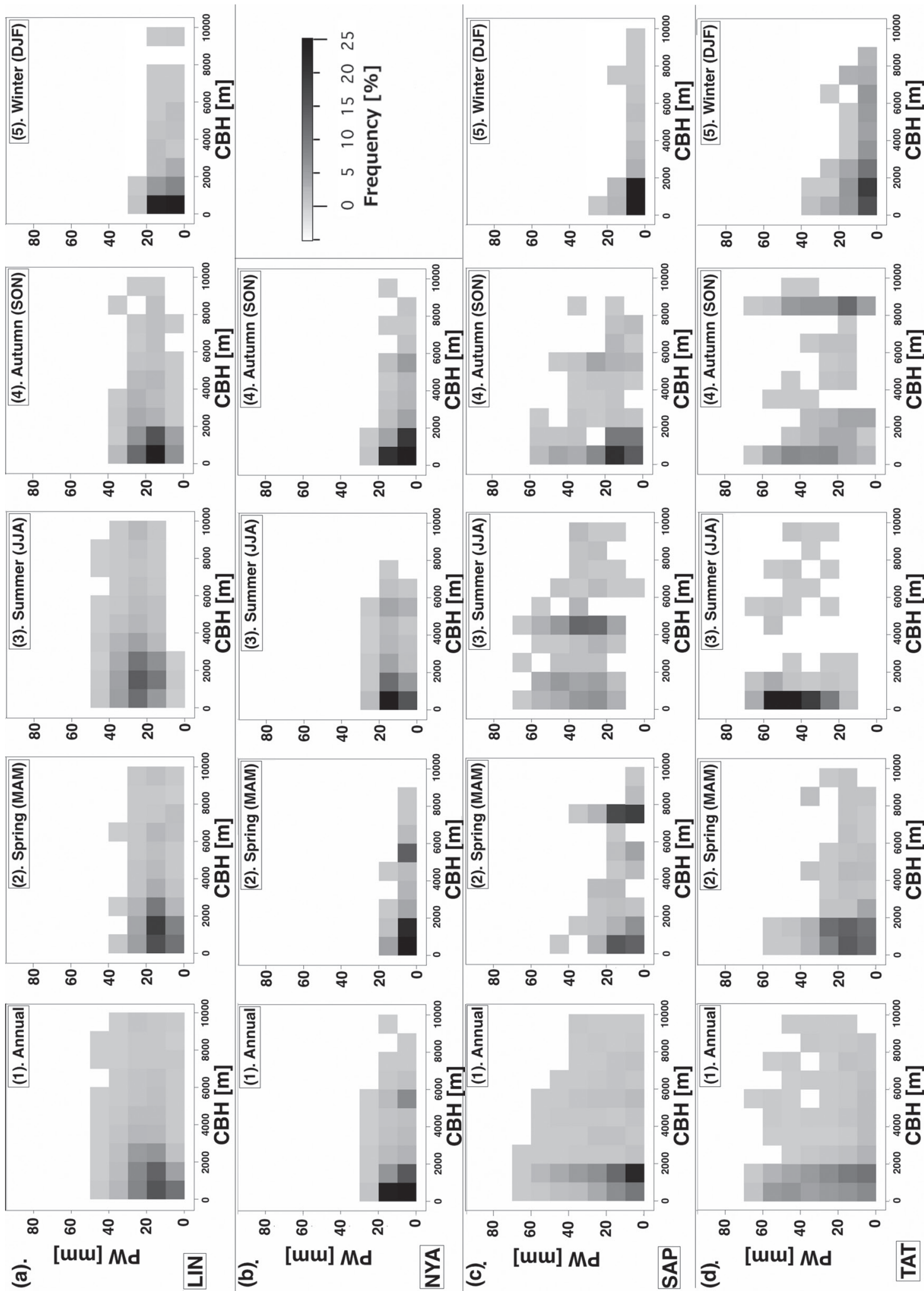

Fig. 12. Joint frequencies between $\mathrm{CBH}$ and $\mathrm{PW}$ at four stations. 
(a).

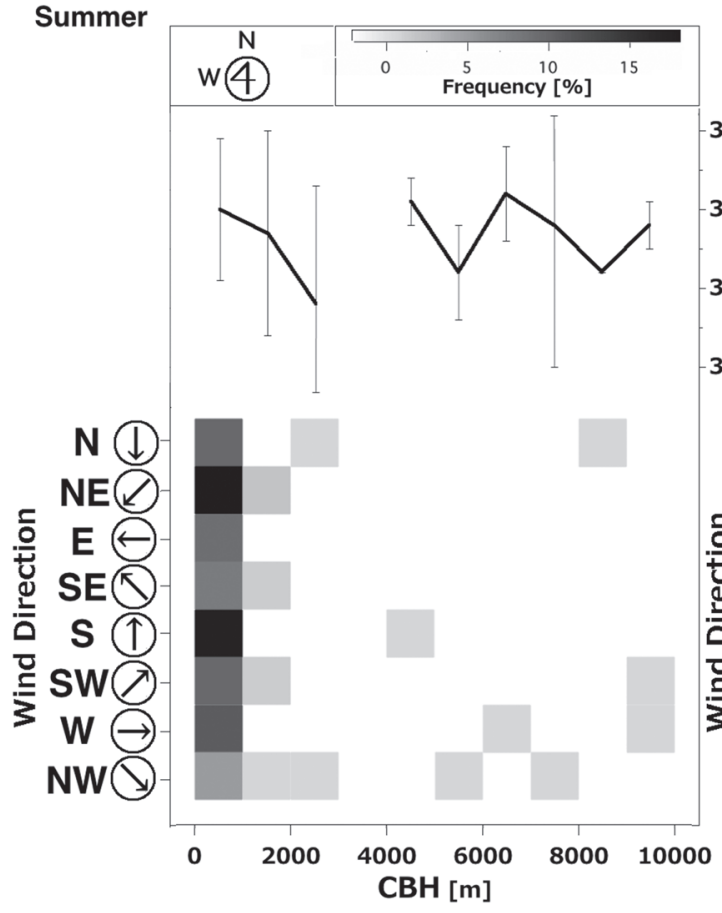

(b).

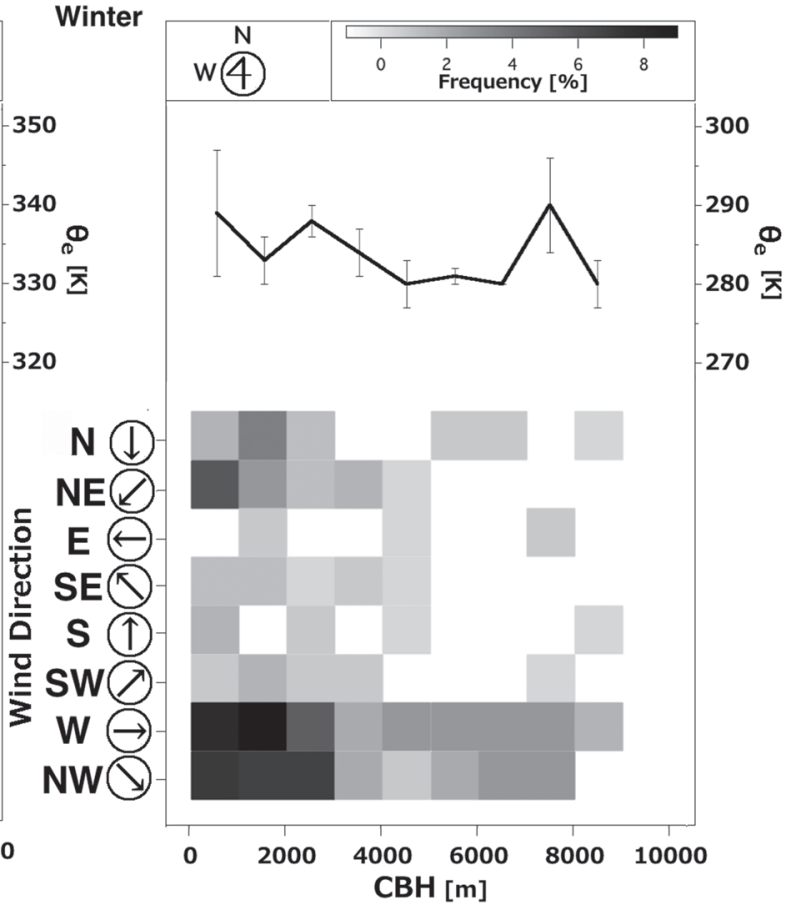

Fig. 13. Joint frequencies between CBH and surface wind direction at TAT for (a) summer and (b) winter seasons.

tion and the calculated DLR at eight BSRN stations. $\mathrm{CRF}$ and $\mathrm{CRC}$ varied widely, from -21 to $92 \mathrm{~W} \mathrm{~m}^{-2}$ and from $-6 \%$ to $38 \%$, respectively. The average of cloud radiative effect increased with increasing SDI and with decreasing PW. The distribution of the cloud effect varied greatly when the cloud cover was high and PW was small. Two results of this study are different from those of Stephens et al. (2012): large negative values of cloud radiative effect were observed in the polar region and were attributed to temperature inversions; and the joint distribution of cloud radiative effect and column water vapor amount was widely scattered owing to the use of in situ observations for near-surface atmosphere and cloud cover.

At four sites (NYA, LIN, SAP, and TAT), we compared $\mathrm{CBH}$ to the cloud radiative effect. Average CRC mostly showed an inverse relationship with $\mathrm{CBH}$, although the average $\mathrm{CRC}$ of low clouds increased with increasing $\mathrm{CBH}$ when the $\mathrm{CBH}$ was less than $2 \mathrm{~km}$ at TAT. This phenomenon occurred because the unusual relationship between $\mathrm{CBH}$ and $\mathrm{CRF}$ for summer and winter seasons affects atmospheric humidity and $\mathrm{CBH}$. The incidence of different cloud base heights was affected by wind direction. The present study used ground-based observation targets, mainly low clouds and surface water vapor, which are difficult to estimate by satellite observation, and showed the variability in the low cloud effect, a pattern caused by regional and seasonal characteristics.

\section{Acknowledgments}

The present study was partially supported by Grantin-Aid for Scientific Research on Innovative Areas No. 22106004 from MEXT, Japan.

\section{References}

Arnfield, A. J., 1979: Evaluation of empirical expressions for the estimation of hourly and daily totals of atmospheric longwave emission under all sky conditions. Quart. J. Roy. Meteor, Soc., 105, 1041-1052.

Berk, A., L. S. Bernstein, and D. C. Robertson, 1987: MODTRAN: A moderate resolution model for LOWTRAN 7. Report AFGL-TR-89-0122, US Air Force Philips Laboratory, Nascom Air Force Base, MA, USA.

Brunt, D., 1932: Notes on radiation in the atmosphere. Quart. J. Roy. Meteor. Soc., 58, 389-418.

Chen, Y., F. Aires, J. A. Francis, and J. R. Miller, 2006: Observed relationship between Arctic longwave cloud forcing and cloud parameters using a neural network. 
Bull. Amer. Meteor. Soc., 15, 4087-4104.

Curry, J. A., W. B. Rossow, D. Randall, and J. L. Schramm, 1996: Overview of Arctic cloud and radiation characteristics. J. Climate, 9, 1731-1764.

Deacon, E. L., 1970: The derivation of Swinbank's longwave radiation formula. Quart. J. Roy. Meteor. Soc., 96, 313-319.

Henderson, D. S., T. L'Ecuyer, G. Stephens, P. Partain, and M. Sekiguchi, 2013: A multisensor perspective on the radiative impacts of clouds and aerosols. J. Appl. Meteor. Climatol., 52, 853-871.

Hirano, J., and J. Matsumoto, 2011; Secular and seasonal variations of winter monsoon weather patterns in Japan since the early 20th century. Int. J. Climatol. 31, 2330-2337.

Idso, S. B., and R. D. Jackson, 1969: Thermal radiation from the atmosphere. J. Geophys. Res., 74, 53975403.

Jhun, J.-G., and E.-J. Lee, 2004; A new East Asian winter monsoon index and associated characteristics of the winter monsoon. J. Climate, 17, 711-726.

Keeling, R. F., S. C. Piper, A. F. Bollenbacher, and J. S. Walker, 2009: Atmospheric $\mathrm{CO}_{2}$ records from sites in the SIO air sampling network. Trends: A Compendium of Data on Global Change. Carbon Dioxide Information Analysis Center, Oak Ridge National Laboratory, U.S. Department of Energy, Oak Ridge, Tenn., U.S.A., doi:10.3334/CDIAC/atg.035.

King, J. C., 1996: Longwave atmospheric radiation over Antarctica. Antarctic. Sci., 8, 105-109.

Long, C. N., and T. P. Ackerman, 2000; Identification of clear skies from broadband pyranometer measurements and calculation of downwelling shortwave cloud effects. J. Geophys. Res., 105, 15609-15626.

Ohmura, A., E. G. Dutton, B. Forgan, C. Fröhlich, H. Gilgen, H. Hegner, A. Heimo, G. K. Langlo, B. McArthur, G. Müller, R. Philipona, R. Pinker, C. H. Whitlock, K. Dehne, and M. Wild, 1998: Baseline Surface Radiation Network (BSRN/WCRP), a new precision radiometry for climate research. Bull. Amer. Meteor. Soc., 79, 2115-2136.

Payne, R. E., 2004: An All-thermistor pyrgeometer. WHOI2004-07, Woods Hole Oceanographic Institution, MA, USA.

Persson, P. G. O., C. W. Fairall, E. L. Andreas, P. S. Guest, and D. K. Perovich, 2002: Measurements near the Atmospheric Surface Flux Group tower at SHEBA: Near-surface conditions and surface energy budget. J. Geophys. Res., 107, No. C10, 8045, doi:10.1029/2000JC000705.

Philipona, R., B. Dürr, and C. Marty, 2004: Greenhouse effect and altitude gradients over the Alps by surface longwave radiation measurements and model calcu- lated LOR. Theor. Appl. Climatol., 77, 1-7.

Phillpot, H. R., and J. W. Zillman, 1970: The surface temperature inversion over the Antarctic continent. $J$. Geophys. Res., 75, 4161-4169.

Ritter, B., and J.-F. Geleyn, 1992: A comprehensive radiation scheme for numerical weather prediction models with potential applications in climate simulations. Mon. Wea. Rev., 120, 303-324.

Schmidt, G. A., R. A. Ruedy, R. L. Miller, and A. A. Lacis, 2010: Attribution of the present-day total greenhouse effect. J. Geophys. Res., 115, D20106, doi:10.1029/2010JD014287.

Sekiguchi, M., and T. Nakajima, 2008: A k-distribution-based radiation code and its computational optimization for an atmospheric general circulation model. J. Quant. Spectrosc. Radiat. Transfer, 109, 2779-2793.

Sellers, W. D., 1965: Physical climatology. University of Chicago Press, Chicago.

Shimizu, A., N. Sugimoto, I. Matsui, 2010: Detailed description of data processing system for lidar network in East Asia. Proceeding of 25th International Laser Radar Conference, St. Petersburg, Russia, 911-913.

Shupe, M. D., and J. M. Intrieri, 2004: Cloud radiative forcing of the Arctic surface: The influence of cloud properties, surface albedo, and solar zenith angle. $J$. Climate, 17, 616-628.

Sohn, B. J., and R. Bennartz, 2008: Contribution of water vapor to observational estimates of longwave cloud radiative forcing. J. Geophys. Res., 113, doi: $10.1029 / 200=J D 010053$.

Stephens, G. L., 2005: Cloud feedbacks in the climate system: A critical review. J. Climate, 18, 237-273.

Stephens, G. L., M. Wild, P. W. Stackhouse Jr., T. L'ecuyer, S. Kato, and D. S. Henderson, 2012: The global character of the flux of downward longwave radiation. $J$. Climate, 25, 2329-2340.

Stone, R. S., 1993: Properties of austral winter clouds derived from radiometric profiles at the South Pole. $J$. Geophys. Res., 8, 12961-12972.

Swinbank, W. C., 1963: Long-wave radiation from clear skies. Quart. J. Roy. Meteor. Soc., 89, 339-348.

Wang, B., and L. Ho, 2002: Rainy season of the Asian-Pacific summer monsoon. J. Climate, 15, 386-398.

Yamada, K., T. Hayasaka, and H. Iwabuchi, 2012: Contributing factors to downward longwave radiation at the Earth's surface. SOLA, 8, 94-97.

Yamamoto, G., and T. Sasamori, 1954: Measurement of atmospheric radiation. Sci. Rep. Tohoku Univ. Ser. 5, Geophys., 6, 19-31. 